\title{
The role of micronized progesterone in preterm labour
}

\author{
Prinka Bajaj ${ }^{1}$, Sandhya Jain ${ }^{2, *}$, Seema Pundir ${ }^{3}$, Ritu Khatuja ${ }^{4}$ \\ ${ }^{1}$ DNB Resident, ${ }^{2} \mathrm{CMO}$ (NFSG), ${ }^{3}$ Specialist, ${ }^{4}$ Assistant Professor, Dept. of Obstetrics and Gynaecology, Baba Saheb Ambedkar \\ Hospital and Medical College, Rohini, New Delhi, India
}

*Corresponding Author:

Email: sandhya.jain29@gmail.com

\begin{abstract}
Objective: To study the role of intravaginal micronized progesterone in preterm labour in prolonging the pregnancy up to term and thus improving neonatal outcome

Materials and Methods: A prospective randomized study wherein 100 pregnant women between 26-34 weeks of pregnancy admitted to labour ward with s/s of preterm labour were included in the study. After initial management with tocolytics and antenatal steroids, when the labour got arrested these women were randomly divided into two groups 1and 2 . Group 1 received $200 \mathrm{ug}$ of intravaginal micronized progesterone from inclusion in the study to 36 weeks or till delivery whichever was earlier. Group 2 received only supportive therapy. None of women received oral tocolytics after initial arrest of labour. All women were followed up till delivery and obstetric outcome noted

Primary variables were prolongation of pregnancy from inclusion in study to delivery interval, gestation age at delivery. Neonatal outcome variables were birth weight, need for NICU transfer, length of stay in NICU and neonatal complications

The results observed were subjected to statistical analysis by SPSS-13 unpaired student t-test, Mann-Whitney for quantitative variables and Chi-square/fisher exact for qualitative variables

Results: The two groups were comparable in term of age, parity and rural/urban status. Baseline presentation characteristics of the two groups such as period of gestation, number of uterine contractions per 10 minutes, cervical dilatation and, cervical effacement were also comparable ( $\mathrm{p}$ value $<0.05$ ). Mean gestational age at delivery in group 1 was significantly more than group 2 (36.808 weeks vs. 34.078 weeks). Patient delivering beyond 37 weeks of gestation were significantly more in group 1 (60\%vs $14 \%$ ). Prolongation of pregnancy was significantly more in group 1, mean no. of days being $34 \pm 15.25$ and $24.22 \pm 12.73$ in group $1 \& 2$ respectively. Neonatal outcome in terms of birth weight was significantly better in group 1.mean birth weight being $2675.2 \pm 382.20$ and $2393.2 \pm 378.05$ in group1 and 2 respectively. Neonatal complications in terms of need for NICU admission, RDS, sepsis and mechanical ventilation were more in group 2.

Conclusion: In preterm labour once the labour is arrested with tocolytics, intravaginal micronized progesterone therapy is effective in prolonging the pregnancy and thus increasing the gestational age at delivery. Neonatal outcome is improved because of increased birth weight and lesser complications.
\end{abstract}

Keywords: Prematurity, Preterm labour, Tocolytics, Micronized progesterone.

\section{Introduction}

Prematurity as a consequence of preterm labour accounts for $75-80 \%$ of neonatal morbidity and mortality. ${ }^{1}$ Of the survivors, $10 \%$ to $15 \%$ have significant handicaps. ${ }^{2}$ Survival of the preterm infant is related directly to the gestational age at delivery. ${ }^{3}$ The incidence of preterm labour has remained at $9-11 \%$ of all live births despite the use of tocolytic agents. ${ }^{4}$

According to world health organization, a preterm birth is defined as birth before 37 completed weeks of gestation. ${ }^{2}$ Traditionally preterm labour is defined as uterine contractions that result in cervical changes at less than 37 weeks gestation. ${ }^{4}$

Tocolytic drugs are the corner stone of primary pharmacological management of preterm labour ${ }^{5}$. It is clear from the literature, that these drugs are effective in delaying delivery for at least 24-48 hours. Unfortunately this modest delay may not be sufficient to produce a reduced perinatal mortality. Therefore many of these patients subsequently develop recurrent premature labour and deliver prematurely. Adjuvant therapy to prevent this could be a missing element in the treatment of these women. ${ }^{6}$
Progesterone treatment following successful tocolysis may reduce the risk of subsequent preterm labour thereby prolonging the period of gestation and possibly improving infant outcomes. Progesterone is essential for maintenance of uterine quiescence throughout the pregnancy. It does this by suppressing genes necessary for uterine contractility, up regulating systems like nitric oxide that cause relaxation and suppressing release of cytokines and prostaglandins. ${ }^{7}$

The prophylactic administration of progesterone beginning in midgestation to women who previously had a preterm birth has been shown to halve the rate of recurrence. However a strategy in which therapeutic intervention is limited to women with a previous preterm delivery is likely to have a small effect on the overall rate of prematurity because only about $10 \%$ of spontaneous early preterm births occur in women with this history. ${ }^{8}$ As progesterone supplementation has shown considerable promise in women who have had a previous preterm birth, it is a natural progression to consider a trial using it for secondary prevention.

Hence the present study was conducted to assess the efficacy of vaginal progesterone in prolonging the pregnancy in patients presenting with spontaneous 
preterm labour and decreasing the neonatal morbidity and mortality.

\section{Materials and Methods}

A prospective randomized control study was conducted in the department of Obstetrics and Gynaecology of Dr Baba Saheb Ambedkar Hospital [Government of NCT, Delhi] Rohini, New Delhi. The Ethics Committee of the Hospital approved the study.

The pregnant women with period of gestation between 26 to 34 weeks, who were admitted with preterm labour, formed the eligible population. They were evaluated by a thorough history, general physical, systemic and obstetric examination and routine antenatal investigations including obstetric ultrasound were done. Preterm labour was defined as the presence of regular and painful uterine contractions at the rate of more than or equal to 2 contractions in 10 minutes with evidence of cervical changes such as effacement and/or dilatation, by manual examination. All patients were initially managed for preterm labour with tocolytics, steroids and antibiotics prophylaxis. Once the labour got arrested, which was defined as a 12 hour contraction free period with tocolytics, these patients were enrolled in study after applying inclusion and exclusion criteria. Informed consent was taken after counseling the patients. Inclusion criteria were singleton pregnancy, intact fetal membranes and cervical dilatation less than $3 \mathrm{cms}$. Exclusion criteria were multiple pregnancy, placenta previa, Preterm premature rupture of membranes at presentation, preexisting hypertension, maternal seizure disorder, active or history of thromboembolic disease, maternal liver disease, known sensitivity to progesterone and fetus with congenital malformations

Patients were randomly divided into two groups having 50 women in each group by computer generated randomization tables. Women enrolled as cases [Group I $(\mathrm{n}=50)]$ received daily doses of $200 \mathrm{mg}$ natural micronized progesterone administered vaginally from the time of randomization until 36 weeks gestation or until the delivery of the fetus if sooner. Group II $(n=50)$ were included as control subjects and received no drug.

Assuming a difference of 1 week or more in the period of gestation to be significant and taking 5\% level of significance, the required sample size was found out to be 46 patients in each group. The power of such a procedure was $91 \%$.

Once the subjects in both the groups became stabilized and had relaxed uterus, they were discharged and monitored on outdoor basis by regular antenatal checkups till delivery. During the study period, no patient received oral tocolytics. They were contacted telephonically also to ensure compliance with progesterone. Various outcomes to be monitored were recorded from case records of mother and baby.

Primary outcome variable were inclusion in study to delivery interval and gestational age at delivery. Secondary variables were neonatal birth weight, need for NICU admission and neonatal complications.

All Statistical analysis were performed using statistical package for social science, version 13 (SPSS13). Normality of distribution of continuous variables was first tested and unpaired student t-test was applied for baseline quantitative variables if data follows normal distribution otherwise Mann-Whitney test was applied. Chi square/fisher exact (where applicable) was applied for qualitative outcome variables. P value $<0.05$ was considered as statistically significant.

\section{Observations and Results}

There was no significant difference between the two groups in their demographic characteristics. The randomly allocated groups were comparable in terms of age, parity, region at the time of inclusion in study. Age varied from 19-35 yrs, mean age being22.76 \pm 2.72 and $23.66 \pm 3.55$ in group I \& II respectively. Parity varied from $0-4$, median parity observed in both groups was1.Majority belonged to rural area. (Table 1)

Table 1:

\begin{tabular}{|l|c|c|c|}
\hline & Group 1 & Group 2 & P value \\
\hline Age & & & \\
Mean Age \pm SD & $22.76 \pm 2.72$ & $23.66 \pm 3.55$ & 0.07 \\
\hline Rural/ Urban & $38(76 \%)$ & $39(78 \%)$ & 0.812 \\
Rural & $12(24 \%)$ & $11(22 \%)$ & \\
Urban & $0-3$ & $0-4$ & 0.665 \\
\hline $\begin{array}{l}\text { Parity } \\
\text { Range }\end{array}$ & 1 & 1 & \\
Median & \multicolumn{2}{|l}{} \\
\hline
\end{tabular}

Demographic profile

Both the groups were comparable with regard to clinical presentation characteristics such as gestational age, the number of uterine contractions per 10 minutes and cervical changes (dilatation and effacement) at the time of admission. Period of gestation at admission varied from 26 to 34 weeks but maximum patients presented at 30-34 weeks gestation in both groups (86\% and $84 \%$ in group $1 \& 2$ respectively). Mean gestation age was $31.96 \pm 1.85 \& 3150 \pm 1.81$ weeks in the two groups respectively. The mean number of uterine contractions per ten minutes was $2.16 \pm 0.37$ and $2.12 \pm$ 
0.32 in Group I \& II respectively $(\mathrm{p}=0.56)$. No significant difference in cervical dilatation (1.48 vs 1.42 $\mathrm{cm} ; \mathrm{p}=0.27)$ and cervical effacement $(43.4 \%$ vs $41.6 \%$; $\mathrm{p}=0.15$ ) was seen between the two groups. (Table 2)

Table 2:

\begin{tabular}{|l|c|c|c|}
\hline & Group 1 & Group 2 & P value \\
\hline $\begin{array}{l}\text { Period of gestation } \\
\text { Mean } \pm \text { SD }\end{array}$ & $31.96 \pm 1.85$ & $31.50 \pm 1.81$ & 0.10 \\
\hline $\begin{array}{l}\text { No. of Uterine } \\
\text { contractions } \\
\text { Mean } \pm \text { SD }\end{array}$ & $2.16 \pm 0.37$ & $2.12 \pm 0.32$ & 0.56 \\
\hline $\begin{array}{l}\text { Cervical Dilatation } \\
\text { Mean } \pm \text { SD }\end{array}$ & $1.48 \pm 0.50$ & $1.42 \pm 0.49$ & 0.27 \\
\hline $\begin{array}{l}\text { Cervical Effacement } \\
\text { Mean } \pm \text { SD }\end{array}$ & $43.4 \pm 10.02$ & $41.6 \pm 7.102$ & 0.15 \\
\hline
\end{tabular}

Baseline Presentation Characterstics at the time of inclusion in the Study

In Group I, the mean gestational age at delivery was $36.808 \pm 1.70$ weeks whereas in Group II, it was found to be $34.978 \pm 1.81$ weeks. In Group I, $60 \%$ of the patients delivered at more than 37 weeks as compared to $14 \%$ in Group II. Significant difference was found between the two groups $(\mathrm{p}=0.00)$. (Table 3)

Table 3:

\begin{tabular}{|c|c|c|c|c|}
\hline \multirow[t]{2}{*}{ POG at delivery } & \multicolumn{2}{|c|}{ Group I } & \multicolumn{2}{|c|}{ Group II } \\
\hline & Frequency & percentage & Frequency & Percentage \\
\hline $26.1-30$ & 0 & 0 & 0 & 0 \\
\hline $30.1-34$ & 4 & 8 & 12 & 24 \\
\hline $34.1-37$ & 16 & 32 & 31 & 62 \\
\hline$>37$ & 30 & 60 & 7 & 14 \\
\hline Total & 50 & 100 & 50 & 100 \\
\hline Mean & \multicolumn{2}{|c|}{36.808} & \multicolumn{2}{|c|}{34.978} \\
\hline Std. Dev & \multicolumn{2}{|c|}{1.70} & \multicolumn{2}{|c|}{1.81} \\
\hline p-value & \multicolumn{4}{|c|}{0.00} \\
\hline
\end{tabular}

Gestational age at delivery

The mean number of days by which pregnancy was prolonged was $34 \pm 15.25$ days and $24.22 \pm 12.73$ in Group I and in Group II respectively. This difference in prolongation of gestation in between the two groups was significant $(\mathrm{p}=0.00038)$. (Table 4)

Table 4:

\begin{tabular}{|l|c|c|c|}
\hline \multicolumn{1}{|c|}{ Prolongation of Pregnancy (in days) } & Group I & Group II & \multirow{2}{*}{0.00038} \\
\hline Mean & 34.0 & 24.22 & \\
\hline Standard. Deviation & 15.25 & 12.73 & \\
\hline
\end{tabular}

Inclusion in study to delivery interval

No significant side effects were noted with progesterone except mild vaginal discharge in 2 patients. Mean number of days of progesterone use in group I was $24.46 \pm 12.236$

The mean birth weight in Group I was $2675.2 \pm$ 382.20 grams and in Group II was $2393.2+378.05$ grams. $70 \%$ of neonates in Group I had birth weight more than 2500 grams as compared to $36 \%$ in Group II.

The difference between the mean birth weight of the two groups was statistically significant $(\mathrm{p}=0.00017)$. (Table 5)

Table 5:

\begin{tabular}{|l|c|c|c|c|}
\hline \multirow{2}{*}{$\begin{array}{c}\text { Birth weight } \\
\text { (in grams) }\end{array}$} & \multicolumn{2}{|c|}{ Group I } & \multicolumn{2}{c|}{ Group II } \\
\cline { 2 - 5 } & Frequency & percentage & Frequency & percentage \\
\hline$<1500$ & 1 & 2 & 1 & 2 \\
\hline $1500-2000$ & 1 & 2 & 6 & 12 \\
\hline $2000-2500$ & 13 & 26 & 25 & 50 \\
\hline$>2500$ & 35 & 70 & 18 & 36 \\
\hline
\end{tabular}




\begin{tabular}{|c|c|c|c|c|}
\hline Total & 50 & 100 & 50 & 100 \\
\hline Mean & \multicolumn{2}{|c|}{2675.2} & \multicolumn{2}{|c|}{2393.2} \\
\hline Std. Deviation & \multicolumn{2}{|c|}{382.20} & \multicolumn{2}{|c|}{378.05} \\
\hline p-value & \multicolumn{4}{|c|}{0.00017} \\
\hline
\end{tabular}

Neonatal Birth Weight

More neonates needed admission to NICU in group II (24\% in group II and $14 \%$ in group I) and length of nursery stay was also more in group II, mean stay being $8.41 \pm 4.461$ in group II and $7.71 \pm 2.870$ in group I.
Neonatal complications were more in group II RDS $(18 \%$ vs $10 \%)$, sepsis (8\%vs $4 \%)$ and need for mechanical ventilation (6\% vs $4 \%$ ). (Table 6)

Table 6:

\begin{tabular}{|l|c|c|c|c|}
\hline & Group I & \multicolumn{2}{c|}{ Group II } \\
\hline Nursery Admission & Frequency & $\%$ & Frequency & $\%$ \\
\hline Admitted & 7 & 14 & 12 & 24 \\
\hline Nursery stay in days & Mean & SD & Mean & SD \\
\hline & 7.71 & 2.870 & 8.41 & 4.461 \\
\hline Neonatal Complications & Frequency & $\%$ & Frequency & $\%$ \\
\hline RDS & 5 & 10 & 9 & 18 \\
\hline Sepsis & 2 & 4 & 4 & 8 \\
\hline MV & 2 & 4 & 3 & 6 \\
\hline
\end{tabular}

Neonatal Parameters

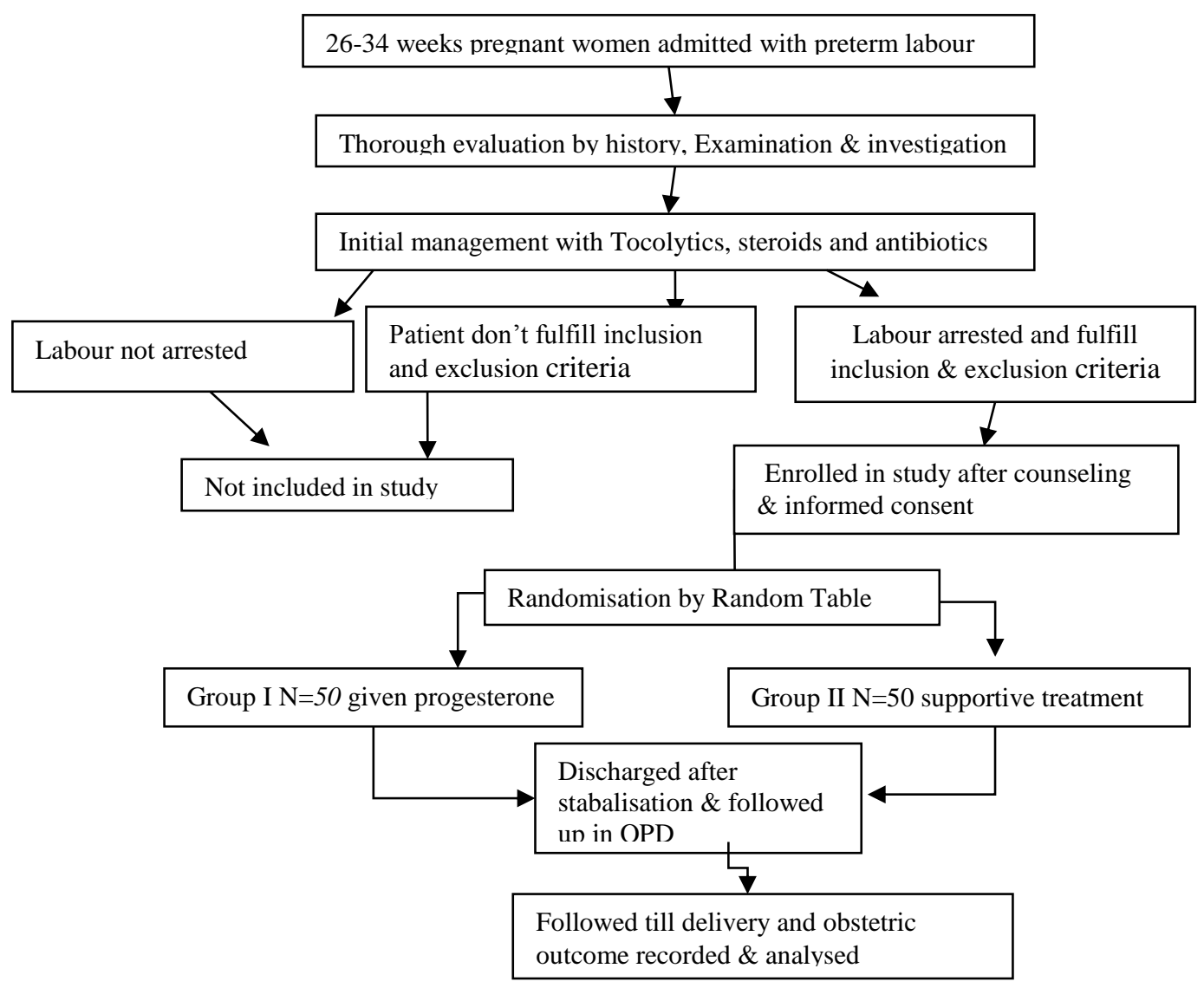

Fig. 1: Methodology -flow chart 


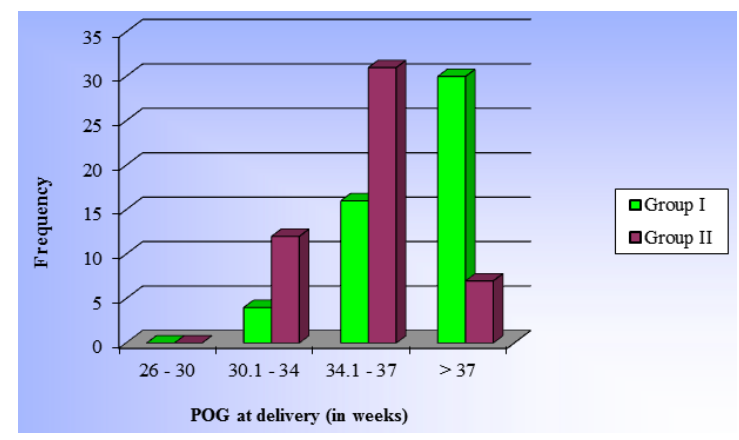

Fig. 2: Gestational age at delivery in study groups

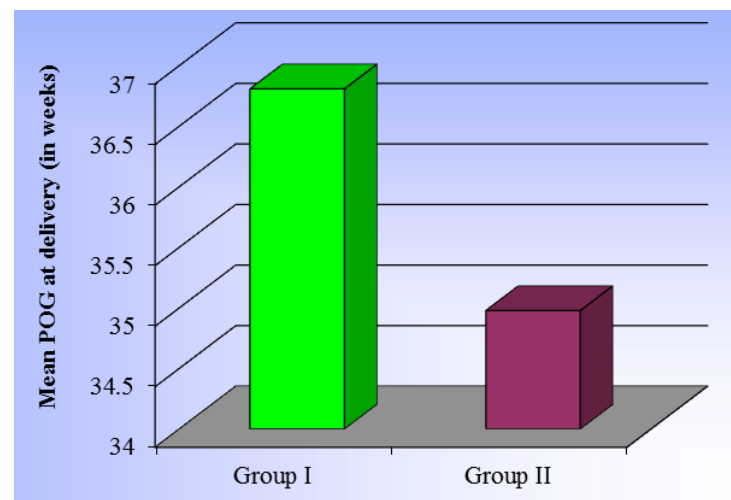

Fig. 3: Mean gestational age at delivery in study groups

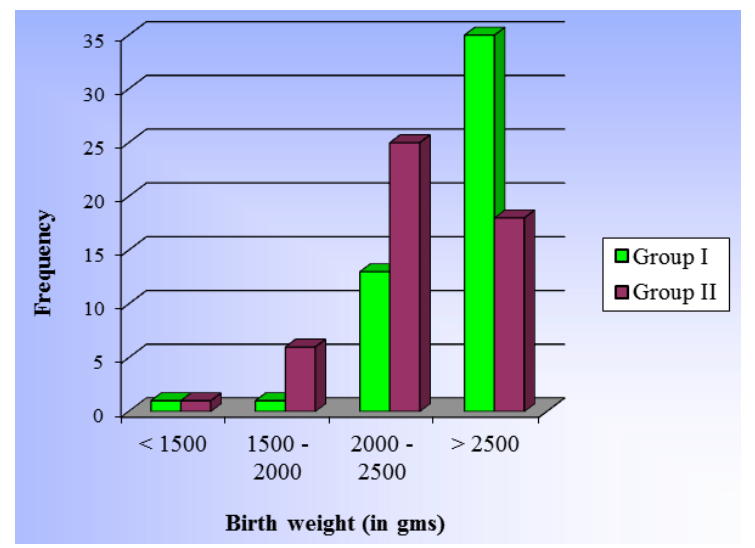

Fig. 4: Birth weight in study population

\section{Discussion}

Preterm birth continues to provide an enormous challenge in the delivery of perinatal health care, estimated to affect approximately 13 million births annually worldwide. ${ }^{9}$ Current management of women in preterm labour includes treatment with a variety of tocolytic medication and antenatal steroid treatment. Tocolytic drugs interrupt or stop uterine contractions. In general, data from randomized trials suggest that tocolytic drugs prolong pregnancy for up to 48 hours. Tocolytics, despite being effective at temporarily arresting premature labour, have not reduced perinatal mortality, may be in part because long term use is either contraindicated or ineffective. ${ }^{10}$ Women who have had an episode of preterm labour arrested by tocolysis comprise a group at especially high risk for preterm delivery. ${ }^{11}$ Progesterone has not been extensively studied in this population. Natural progesterone is free of any disturbing teratogenic, metabolic or hemodynamic effects. A number of studies have established the high bioavailability of vaginal micronized progesterone. ${ }^{12} \mathrm{We}$ therefore conducted this study to evaluate the use of vaginal micronized progesterone to reduce the risk of preterm delivery in this group.

The prolongation of pregnancy was significantly more in progesterone group, inclusion to delivery interval being 34days in group I and 24.22 days in group II. The mean period of gestation at delivery was significantly higher by almost two weeks in women who received progesterone therapy (36.80 vs. 34.97$)$, leading to $40 \%$ higher number of women being delivered after 37 weeks in study group. (60\% vs. $14 \%$ ). Results are similar as reported in literature though progesterone, dose and route are different in various studies. ${ }^{11,13-16}$ Borna et al reported difference in prolongation of pregnancy by 11.5 days while Gargari et al reported it to be 2.6 weeks. Bomba-Opon et al observed a significant reduction in delivery before 34 weeks with vaginal progesterone (9.8\% in progesterone group versus $35.3 \%$ in control group; $\mathrm{p}=0.002$ ). Their results were comparable to our study (8\% versus 24\%). This much difference in gestation age makes significant impact on neonatal prognosis and societal economic burden. Of all early neonatal deaths (deaths within the first 7 days of life) that are not related to congenital malformations, 28\% are due to preterm birth. ${ }^{17}$ The morbidity associated with preterm birth often extends to later life, resulting in enormous physical, psychological and economic costs.Therefore if we take into account the cost of initial nursery care, later medical needs and special expenditures benefits are enormous. Estimates indicate that in 2005 the costs to the United States of America alone in terms of medical and educational expenditure and lost productivity associated with preterm birth were more than US\$ 26.2 billion. ${ }^{17}$

In our study in progesterone group neonatal birth weight was higher by approximately $300 \mathrm{gm}$. (2675.2 gm in group I vs $2393.2 \mathrm{gm}$ in group II) Vaginal progesterone was associated with birth weight of more than $2500 \mathrm{gm}$ in $70 \%$ cases as compared to $36 \%$ in control group. The results were comparable to that observed in literature. In various studies improvement in birth weight ranged from 290-490 gms. ${ }^{11,13-15,18}$

NICU admission were also less in study group $(14 \%$ vs $24 \%)$ with shorter nursery stay(7.71 vs 8.41 days).Neonatal complications like RDS, sepsis, mechanical ventilation were also less in study group. There was one case of neonatal death in Group II. The results were comparable to the previous studies..$^{13,19-21}$

Thus it was observed that adding intravaginal micronised progesterone to patients of preterm labour while adds minimal cost and very few side effects, but 
has a advantage of increasing gestational age at delivery, increasing birth weight and fewer NICU admissions.

\section{Conclusion}

In patients of preterm labour vaginal micronized progesterone when used along with tocolytics and supportive therapy significantly prolongs the pregnancy and hence gestational age at delivery. Progesterone therapy leads to higher number of women reaching term and delivering beyond 37 weeks and also better neonatal outcome in terms of higher birth weight and fewer complications. However small sample size and nonblinded study are the limitations of our study and larger studies are needed to confirm these results and to consider it to include in standard treatment guidelines of preterm labour.

\section{References}

1. Effect of corticosteroids for fetal maturation on perinatal outcomes. NIH Consens Statement. 1994 Feb 28-Mar 2;12(2):1-24.

2. Da Fonesca EB, Bittar RE, Carvalho MHB et al. Prophylactic administration of progesterone by vaginal suppository to reduce the incidence of spontaneous preterm birth in women at increased risk: a randomized placebo controlled double blind study. Am J Obstet Gynecol. 2003;188(2):419-24.

3. Ward RM, Beachy JC. Neonatal complications following preterm birth. Br J Obstet Gynaecol. 2003;110(20):8-16.

4. K Joseph Hurt, Matthew W Guile, Beinstock JL, Fox HE, Wallach EE. John Hopkins Manual of Gynaecology and Obstetrics: Preterm labour. $4^{\text {th }}$ ed. Lippincott Williams and Wilkins. 2011;122-9.

5. Berkman ND, Thorp JM, Lohr KN et al. Tocolytic treatment for the management of preterm labor. A review of the evidence. Am J Obstet Gynecol. 2003;188(6):1648-59.

6. Meirowitz NB, Ananth CV, Smulian JC et al. Value of maintenance therapy with oral tocolytics: a systematic review. J Maternal Fetal Med. 1999;8:177-83.

7. Meis PJ, Connors N. Progesterone treatment to prevent preterm birth. Clin Obstet Gynecol. 2004;47(4):784-95.

8. Fonesca EB et al. Progesterone and the risk of preterm birth among women with a short cervix. N Engl J Med. 2007;357(5):462-469.

9. Jodie M Dodd, Caroline A Crowther. The role of progesterone in prevention of preterm birth. Int J Women Health. 2009;1:73-84.

10. Goldenberg RL, Rouse DJ. Prevention of premature birth. N Engl J Med 1998;339(5):313-20.

11. Borna S, Sahabi N. Progesterone for maintenance tocolytic therapy after threatened preterm labour: a randomised controlled trial. Aust NZ J Obstet Gynecol. 2008;48(1):58-63.

12. Alexander NJ, Baker E, Kaptein M et al. Why consider vaginal drug administration? Fertil Steril. 2004;82(1):112.

13. Arikan I, Barut A, Harma M et al. Effect of progesterone as a tocolytic and in maintenance therapy during preterm labor. Gynecol Obstet Invest. 2011;72(4):269-73.

14. Bomba-Opon DA, Kosinska-Kaczynska K, Kosinski P et al. Vaginal progesterone after tocolytic therapy in threatened preterm labor. $\mathrm{J}$ Matern Fetal Neonatal Med. 2012;25(7):1156-9.
15. Gargari SS, Habibolahi M, Zonobi ZKZ, Sarfjoo FS, Robati AK, Etemad R, et al. Outcome of Vaginal Progesterone as a Tocolytic Agent: Randomized Clinical Trial. ISRN Obstet Gynecol. 2012;(2012):1-5.

16. Su LL, Samuel M, Chong YS. Progestational agents for treating threatened or established preterm labour. Cochrane Database Syst Review 2010(1):CD006770.

17. Stacy Beck, Daniel Wojdyla, Lale Say et al. The worldwide incidence of preterm birth: a systematic review of maternal mortality and morbidity. Bulletin of the World Health Organization. 2010;88(1):31-38.

18. Facchinetti F, Paganelli S, Comitini G et al. Cervical length changes during preterm cervical ripening: Effects of 17 $\alpha$-hydroxyprogesterone caproate. Am J Obstet Gynecol. 2007;196:421-7.

19. Fonesca EB et al. Progesterone and the risk of preterm birth among women with a short cervix. N Engl J Med. 2007;357(5):462-9.

20. De Franco EA, O'Brien JM, Adair CD et al. Vaginal progesterone is associated with a decrease in risk for early preterm birth and improved neonatal outcome in women with a short cervix: a secondary analysis from a randomized, double-blind, placebo-controlled trial. Ultrasound Obstet Gynecol. 2007;30(5):697-705.

21. Hassan SS, Romero R, Vidyadhari D et al. Vaginal progesterone reduces the rate of preterm birth in women with a sonographic short cervix: a multicenter, randomized, double-blind, placebo-controlled trial. Ultrasound Obstet Gynecol. 2011;38(1):18-31. 